\title{
Migration and Remigration of Male Household Heads in Turkey, 1963-1973*
}

Insan Tunalı

Koç University, Istanbul, and The Economics Institute, Boulder, Colorado

Urbanization is a ubiquitous phenomenon that characterizes the recent experiences of Third World countries. Turkey's experience during the 1950-80 period is no exception. In this 30-year period, Turkey's population in rural areas increased by $60 \%$, while its urban population nearly quadrupled. It is estimated that some 10 million rural inhabitants migrated to the cities during this time, a staggering figure, which equals nearly one-fourth of the 1980 population. ${ }^{1}$ Apart from urbanization, a second major pattern that Turkey shares with other Third World countries is directionality in the form of flows that originate in the economically backward areas (especially the eastern parts of the country) and end in the more dynamic ones (especially the western regions).

In this article, I offer evidence from the 1963-73 period regarding the determinants of individual migration and remigration decisions within Turkey. By exploiting a rich longitudinal data set, my aim is to contribute to the existing literature on several fronts. First, I analyze the impact of regional and macroeconomic variables on migration status at the same time that I control for a rich set of personal characteristics, including information on past migration histories. This enables me to determine the relative significance of the forces that influence individual migration experiences. Second, I formally introduce remigration as an option available at the time the initial migration decision is made. This allows for an examination of the factors accounting for stepwise and circular moves, something that has been ignored in previous studies. Third, I conduct a systematic study of the determinants of various types of migration and remigration. I achieve this by assessing migration status at the province, district, and village levels over 5- and 10 -year intervals and by drawing qualitative and quantitative comparisons and contrasts between the findings from the different definitions.

C 1996 by The University of Chicago. All rights reserved.

0013-0079/97/4501-0001\$01.00 
Fourth, I show how the microeconometric evidence can be used to entertain counterfactuals that would help investigate the policy implications of the findings. While a comprehensive exercise of this sort would warrant a separate article on the subject, the examples provided go a long way in demonstrating the usefulness of the methodology.

I begin with a brief overview of the aggregate migration flows. Then I present the theoretical and statistical framework used for studying the determinants of migration and remigration. This is followed by a description of the data and a discussion of the methodological issues. The systematic study of the qualitative as well as the quantitative impact of the explanatory variables on the migration and the remigration decisions is the main subject of the empirical section. I first examine a three-way choice, in which individuals sort themselves into one of three categories: "stayers," who did not change their residence during the period under study, "one-time movers," who moved only once, and "frequent movers," who moved at least two times. I subsequently examine the evidence concerning return and repeat moves. The final section highlights the substantive findings. Details of the statistical methodology are presented in the appendix.

\section{Migration Flows in Turkey}

The consensus among researchers is that voluntary internal population movements were rather unimportant prior to 1950 and that urbanization became a significant phenomenon from 1950 on. $^{2}$ Between 1927 and 1950, the share of urban localities (defined as those with a population larger than 10,000) in total population increased from $16 \%$ to $19 \%$, during which time the total population increased by some $50 \% .^{3} \mathrm{By}$ 1965 , the population was up by another $50 \%$, with urban residents accounting for $30 \%$ of the total. Major cities-defined as those localities with a population of 100,000 or more-constituted the fastest growing category after 1940, except between 1965 and 1970. By the year 1980, $45 \%$ of Turkey's inhabitants were residing in urban $(10,000+)$ localities, with more than half in the major cities. What makes these patterns interesting for our purposes is the fact that urbanization and internal migration have gone hand in hand.

While the urbanization process has had an impact throughout the country, regional differences in the degree of urbanization have nonetheless been substantial. These differences reflect the pattern of longstanding regional inequalities in the distribution of economic activities and resources. The map in figure 1 is useful for identifying the regional growth centers. The western region has been continually the most urbanized region (over $60 \%$ in 1980) due to the dominant role of İstanbul and its neighboring provinces, which are engaged in manufacturing activity. This region also contains İzmir, which, prior to the $1980 \mathrm{~s}$, was the main port for exports and is the third largest city. The central 


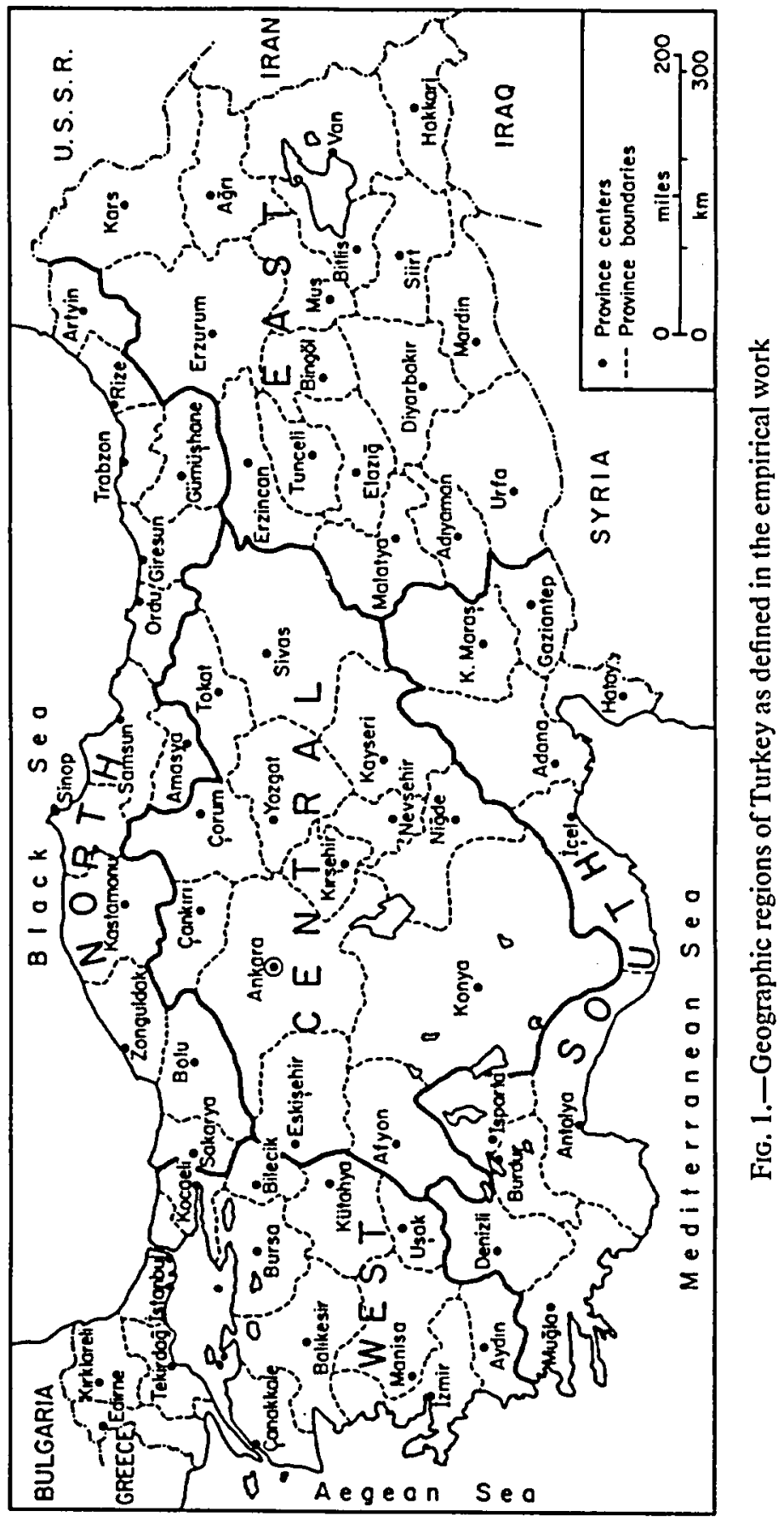


region, the traditional wheat basket of Turkey, went through a remarkable transformation due to the expansion of Ankara, the capital city. About half this region's population lived in cities that had more than 10,000 inhabitants in 1980 . The southern region, with the richest agricultural areas of Turkey, also harbors the industrial region around Adana. In 1980, about $45 \%$ of the inhabitants of the southern region were living in urban localities. The northern and the eastern regions are the least urbanized (25\%-27\% urban in 1980), in part because Turkey's most prominent mountain ranges are located there. With migration as its primary demographic component, these regional differences in urbanization reflect the directional pattern of migration flows in Turkey.

External migrations have also been an important demographic factor. The emigration to western Europe, which began in the mid-1950s and reached sizable magnitudes in the $1960 \mathrm{~s}$, is the most notable of these. Until the migrant flow was curtailed as a result of the depressed economic conditions in western Europe in the late 1970s, some 800,000 workers (plus their dependents) are estimated to have emigrated to western Europe, a figure equivalent to $5 \%$ of the civilian labor force in Turkey in 1977-78. ${ }^{4}$ Unfortunately, due to data constraints that will be described in some detail below, external migrations could not be included in the empirical work reported here.

\section{Theoretical Framework}

There is a long-established tradition in the migration literature that views geographic mobility as a response to regional inequalities. ${ }^{5} \mathrm{Un}$ certainty plays an important role in the place-to-place migration framework. ${ }^{6}$ The outline of the model of individual (household, family) migration behavior that emerges from this literature is as follows. At a point in time, the individual will view the available locations in terms of the probability distribution of the returns to human capital and the costs of moving (which include the moving expenses as well as the adjustment costs). Since the information available is likely to be nonuniform across the various locations, the decision will be affected by what the individual knows about the potential destinations.

If, despite the potential risks due to miscalculation and bad luck, the discounted stream of net returns warrants the costs, a move will take place. If there is more than one such destination, the move will be directed to the location that provides the highest net gain. If the gains from moving do not outweigh the costs, the optimal decision will be to stay at the current location. Since the information set will change as a result of a move, a similar calculation will be made at the new destination. Similarly, if new information becomes available following a stay decision, the calculation will be repeated. In any of these calcu- 
lations, a location at which the individual previously resided would enter the picture in a favorable manner, in the sense that the risks and the costs associated with a move to it will be lower. Taking locality of residence as given, differences among individuals in terms of human and location-specific capital endowment, the costs they face, the type of information they have, and their attitude toward risk will determine the different migration experiences in the population. ${ }^{7}$

The formulation depicted in the preceding summary views the migration decision in a sequential fashion. Remigration takes place because of the individual's inability to judge the earnings prospects correctly. ${ }^{8}$ But remigrations can take place for other reasons as well. There are instances in which individuals plan for subsequent moves at the time they make the original migration decision. Stepwise (or stage) migrations, which often are preconceived repeat moves, and circular migrations, which often are preconceived return moves, fit this characterization. From a policy perspective, it would be useful to know if covariates measured at a given point in time can help sort out the different migrant types. This is the approach I take in this article.

A convenient statistical formulation for studying the migration decision in the human capital and job-search framework is provided by models of discrete choice. In the next subsection I present the discrete choice formulation used in the empirical work. Since the reduced-form nature of the estimated equations make the analysis susceptible to ex post theorizing, I will refrain from repeating the wellrecited hypotheses that link the explanatory variables with the migration outcome. These will be taken up when I discuss the results in the context of the previous findings.

\section{The Statistical Model}

Consider an individual who anticipates three (discounted streams of future) earnings prospects: $y_{\mathrm{s}}^{*}$ if the "stay" option is chosen, $y_{\mathrm{o}}^{*}$ if the "one-time move" option is chosen, and $y_{f}^{*}$ if the "frequent move" option is chosen. The stay option entails staying at the original locality throughout the time horizon, the one-time move option entails moving once and remaining at the destination locality for the remainder of the time horizon, and the frequent move option entails passing through one or more intermediate localities before ending up at the final destination and remaining there for the remainder of the time horizon. The frequent move option allows the anticipated rates of return to change as a result of the intermediate step. For example, training undertaken at the initial destination might augment the individual's earnings at the final destination, making it more desirable than it was to begin with, were the individual to move there directly.

Without loss of generality, we may assume that $y_{0}^{*}$ and $y_{f}^{*}$ denote 
utility streams associated with the earnings prospects net of anticipated moving costs and consider the system of structural equations

$$
\begin{aligned}
& y_{\mathrm{s}}^{*}=\boldsymbol{\alpha}_{\mathrm{s}}^{\prime} \mathrm{x}+v_{\mathrm{s}}, \\
& y_{\mathrm{o}}^{*}=\boldsymbol{\alpha}_{\mathrm{o}}^{\prime} \mathrm{x}+v_{\mathrm{o}}, \\
& y_{\mathrm{f}}^{*}=\boldsymbol{\alpha}_{\mathrm{f}}^{\prime} \mathrm{x}+v_{\mathrm{f}},
\end{aligned}
$$

where $\mathrm{x}$ denotes the vector of explanatory variables; $\alpha_{d}(d=\mathrm{s}, \mathrm{o}, \mathrm{f})$ denotes unknown parameter vectors for stayers, one-time movers, and frequent movers, respectively; and $v$ denotes random disturbances known to the individual but unobserved by the researcher. Define $y_{1}^{*}=y_{0}^{*}-y_{\mathrm{s}}^{*}$ as the net anticipated utility gain from moving once (relative to staying) and define $y_{2}^{*}=y_{f}^{*}-y_{0}^{*}$ as the net anticipated utility gain from moving a second time (relative to moving once), whereby $y_{1}^{*}+y_{2}^{*}$ is the net anticipated gain from moving more than once (relative to staying). The reduced form counterpart of (1)-(3) is

$$
\begin{aligned}
& y_{1}^{*}=\beta_{1}^{\prime} \mathrm{x}+v_{1}, \\
& y_{2}^{*}=\beta_{2}^{\prime} \mathrm{x}+v_{2},
\end{aligned}
$$

where $\boldsymbol{\beta}_{1}=\boldsymbol{\alpha}_{0}-\boldsymbol{\alpha}_{\mathrm{s}}, \boldsymbol{\beta}_{2}=\boldsymbol{\alpha}_{\mathrm{f}}-\boldsymbol{\alpha}_{0}, v_{1}=v_{0}-v_{\mathrm{s}}$, and $v_{2}=v_{\mathrm{f}}-$ $v_{0}$.

Letting

$$
r^{*}=\sup \left\{0, y_{1}^{*}, y_{1}^{*}+y_{2}^{*}\right\}
$$

the decision rule is

$$
\begin{array}{ll}
\text { Stay }(d=\mathrm{s}), & \text { if } r^{*}=0, \\
\text { Move once }(d=\mathrm{o}), & \text { if } r^{*}=y_{1}^{*}, \\
\text { Move more than once }(d=\mathrm{f}), & \text { if } r^{*}=y_{1}^{*}+y_{2}^{*} .
\end{array}
$$

Letting $\boldsymbol{P}_{d}$ denote the $i$ th individual's probability of belonging to subsample $d(d=\mathrm{s}, \mathrm{o}, \mathrm{f})$, the likelihood for the entire sample may be written as

$$
L_{3}=\prod_{d=\mathrm{s}} P_{\mathrm{s}} \cdot \prod_{d=\mathrm{o}} P_{\mathrm{o}} \cdot \prod_{d=\mathrm{f}} P_{\mathrm{f}}
$$


where the subscript $i$ is suppressed for brevity, and $\Sigma_{d} P_{d}=1$. Assuming $v$ 's in (1)-(3) are independently distributed as Extreme Value Type $\mathrm{I},(7)$ gives rise to the multinomial logit model (MLM).

One of the objectives of this article is to shed light on the forces that distinguish returners from repeaters. In evaluating the frequent move alternative $\left(y_{\mathrm{f}}^{*}\right)$, the individual considers the possibility of a repeat (forward) move, as well as a return (backward) move. Letting $y_{\mathrm{n}}^{*}$ and $y_{\mathrm{b}}^{*}$, respectively, denote the net anticipated utility gain from the best repeat and best return sequence (relative to a one-time move), and adding the second subscript " $f$ " (for "forward") and " $b$ " (for "backward") as appropriate, the modification is readily achieved. In place of (3), we get two separate structural equations and, hence, an additional set of reduced-form parameters to estimate. The likelihood function for the four-way logit analysis becomes

$$
L_{4}=\prod_{d=\mathrm{s}} P_{\mathrm{s}} \cdot \prod_{d=\mathrm{o}} P_{\mathrm{o}} \cdot \prod_{d=\mathrm{ff}} P_{\mathrm{ff}} \cdot \prod_{d=\mathrm{fb}} P_{\mathrm{fb}}
$$

One question that comes to mind is whether the determinants of subsequent moves are different from those of a first move and whether repeat and return moves can be lumped together. It is possible to test whether these distinctions are relevant by using the Cramer-Ridder Pooling Test. ${ }^{9}$ Consider the contrast between repeat and return moves. If the moves arise for different sets of reasons, certain types of individuals would opt for the former, while others would opt for the latter. Otherwise all individuals will perceive the two options in like terms. In that case the anticipated earnings net of moving costs under the frequent move option ( $y_{f}^{*}$ ) may be expressed as the same convex linear combination of $y_{\mathbb{f}}^{*}$ and $y_{\mathrm{b}}^{*}$ for all individuals. Consequently the parameters of the structural equations under the return and repeat options will be the same, except for the intercept terms. ${ }^{10}$ The log-likelihood value of the restricted model can be obtained from

$$
\log \hat{L}_{4}^{*}=\log \hat{L}_{3}+N_{\mathrm{ff}} \log N_{\mathrm{ff}}+N_{\mathrm{fb}} \log N_{\mathrm{fb}}-N_{\mathrm{f}} \log N_{\mathrm{f}}
$$

where $\log$ denotes the natural logarithm, $\hat{L}_{3}$ denotes the maximized value of (8), and $N$ 's denote the subsample sizes. The null hypothesis that a repeat and return distinction is superfluous may in turn be tested by forming the Likelihood Ratio statistic that contrasts the loglikelihood values obtained from equations (9) and (10). Under the null hypothesis, the test statistic has a Chi-square distribution with degrees of freedom equaling the number of restrictions (which in our case is the number of explanatory variables). The null hypothesis that subsequent moves are motivated in the same manner as first-time moves can be tested in a similar fashion. 


\section{Data and Empirical Methodology}

The data used in the empirical investigation were extracted from the Male Survey portion of the 1973 Survey of the Structure of Population and Population Problems conducted by Hacettepe Institute of Population Studies (HIPS), Ankara, Turkey. The survey collected retrospective information on lifetime migration and employment histories of one male member (18 years or older) from each household in the sample. This made the detection of multiple (repeat and return) moves possible. The availability of two separate retrospective time series with redundant information made it possible to carry out consistency checks enhancing the recall reliability of the data. The empirical work reported below relies on the 10-year series that I reconstructed according to the internal consistency requirements of these responses.

\section{Definition of Migration and the Working Samples}

Six different definitions of migration were employed in the empirical work. Classification of the individuals according to migration status was based on location information at the province, district, and village levels for the 5-year period 1968-73 and the 10-year period 1963-73." To avoid situations where the migration decision was made by somebody else, only household heads were included in the sample. Since the theoretical framework described above revolves around the potential earnings gain associated with migration, I made every attempt to confine the incidence of migration to locational changes induced by an economic motive. Yet moves can, and do, take place for other reasons. A case in point is provided by military service-related compulsory moves, which constituted the majority of the repeat and return moves encountered in the HIPS data. In constructing the migration history files, respondents who changed residence as a service requirement were treated as residing in the locality where they were prior to the compulsory move during the service period. Other motives frequently cited in the literature include educational and family (marriage) considerations, both of which fall outside the domain of analysis here. ${ }^{12}$

External migrations could not be studied as part of this project, given the information available in the data. Even if additional information were available, institutional rigidities make it inappropriate to include moves abroad as an alternative in the choice set of all individuals. ${ }^{13}$ Retirement-induced decisions to move were another excluded domain. In a country like Turkey where the bulk of retired individuals rely on family and kinship networks for their survival, it does not make much sense to incorporate such moves in a choice framework such as this. Thus, the results reported here pertain to nonretired male household heads, in the 18-65 age bracket in 1973, who participated in the labor market at the time the migration decision was made, and for whom complete migration and employment histories for the relevant 
period as well as information on other variables of interest were available.

\section{Choice of Regressors}

The vast literature on migration suggests that there are many types of migrants, who migrate for a variety of reasons. In order to exploit fully the richness of the data, I followed an exploratory estimation strategy. The explanatory variables were first collected in three nonoverlapping groups that respectively captured the regional, the personal, and the move-related factors. These exclusive specifications were estimated for all six definitions of migration - at the province, district, and village levels, respectively, for the 5- and 10-year periods 1968-73 and 196373-on the basis of which a final hybrid specification was obtained using statistical model selection criteria. ${ }^{14}$ The work reported below pertains to the detailed analysis of the hybrid specification only.

Information on a host of factors that had been isolated as significant determinants of migration in previous studies - such as income, land ownership, and marital status-was available for 1973 only. This precluded inclusion of these factors in the migration equations, which use information available at the time of the decision. Information on household size and composition was not available in the Male Survey. Finally, given the long list of explanatory variables with which I started, interactions and other nonlinearities had to be omitted from the systematic investigation. However, on occasion I did try other specifications to shed further light on the results compiled in the tables. These are reported in the notes.

\section{Empirical Results}

Definitions of the explanatory variables used in the migration equations are given in table 1 . The variable name abbreviations indicated in table 1 will be used when appropriate, to avoid repetition of the longer names. Table $A 1$ in the appendix reports the descriptive statistics for the explanatory variables for the province- and village-level samples for which detailed results from the three-way classification will be presented. The statistics relevant for the repeat and return distinction are collected in table A2 in the appendix. The breakdown of the respective samples according to migration status is also given in those tables.

The reduced-form estimates of equations (4) and (5) based on the three-way classification of the sample are reported in table 2 . Since district- and village-level results were very similar, the former have been excluded from this table. Likelihood Ratio statistics reveal that the estimated models are highly significant. Between $74 \%$ and $88 \%$ of the actual outcomes are correctly predicted. In terms of predictive power, interprovincial models perform better than intraprovincial models and 5-year models do better than 10-year models. Using the 
TABLE 1

Definitions of the Explanatory Variables

\begin{tabular}{|c|c|c|}
\hline Variable & Abbreviation & Definition \\
\hline \multicolumn{3}{|l|}{ Regional variables: } \\
\hline Metropolitan resident* & METRO & $\begin{array}{l}=1 \text { if residing in metropolitan Ankara, } \\
\text { Istanbul, or Izmir; }=0 \text { else }\end{array}$ \\
\hline $\begin{array}{l}\text { Rural resident* } \\
\text { Northern region* }\end{array}$ & $\begin{array}{l}\text { RURAL } \\
\text { NORTH }\end{array}$ & $\begin{array}{l}=1 \text { if residing in a rural locality; }=0 \text { else } \\
=1 \text { if residing in the Northern region; }=0 \\
\text { else }\end{array}$ \\
\hline $\begin{array}{l}\text { Average intraorigin dis- } \\
\text { tance* }\end{array}$ & AIOD & $\begin{array}{l}\text { Radius of a circle with half the area of the to- } \\
\text { tal surface area of the origin province in kilo- } \\
\text { meters }\end{array}$ \\
\hline $\begin{array}{l}\text { Destination-origin dis- } \\
\text { tance* }\end{array}$ & DOD & $\begin{array}{l}\text { Highway distance between province center of } \\
\text { "most likely destination"" and province cen- } \\
\text { ter of origin locality in kilometers }\end{array}$ \\
\hline $\begin{array}{l}\text { Relative province } \\
\text { development index * }\end{array}$ & RPDI & $\begin{array}{l}\text { Index of socieconomic development for "most } \\
\text { likely destination" divided by index of socio- } \\
\text { economic development of province of origin }\end{array}$ \\
\hline \multicolumn{3}{|l|}{ Personal characteristics: } \\
\hline Age* & AGE & Age in years \\
\hline $\begin{array}{l}\text { Schooling } \\
\text { Self-employed in agri- }\end{array}$ & SCH & Years of formal schooling \\
\hline $\begin{array}{l}\text { culture* } \\
\text { Self-emploved outside }\end{array}$ & SEIAG & $=1$ if self-employed in agriculture; $=0$ else \\
\hline agriculture* & SEOAG & $\begin{array}{l}=1 \text { if self-employed outside agriculture (except } \\
\text { for the skilled category); }=0 \text { else }\end{array}$ \\
\hline Skilled* & SKILL & $\begin{array}{l}=1 \text { if skilled employee or professional; }=0 \\
\text { else }\end{array}$ \\
\hline No job security* & NOSEC & $\begin{array}{l}=1 \text { if has no insurance, social security, union, } \\
\text { or employers' association benefits; }=0 \text { else }\end{array}$ \\
\hline Unemployed* & UNEMP & $=1$ if unemployed; $=0$ else \\
\hline First job in agriculture & FJIAG & $\begin{array}{l}=1 \text { if first job held was in agriculture; }=0 \\
\text { else }\end{array}$ \\
\hline \multicolumn{3}{|l|}{ Move-related variables: } \\
\hline Duration* & DUR & Duration of residence in years \\
\hline Tenure* & TEN & $\begin{array}{l}\text { Job tenure in years (current job if UNEMP }= \\
0 \text {; last job if UNEMP }=1 \text { ) }\end{array}$ \\
\hline
\end{tabular}

* Indicates a "period-dependent variable." In this study, all such variables were measured at the beginning of the relevant period: 1963 in the case of 10-year estimates and 1968 in the case of 5-year estimates.

Cramer-Ridder Pooling Test, the null hypothesis that migration and remigration are not distinct states cannot be rejected in the case of 5 -year province-level moves $(P$-value $>.30)$. Evidence against the null hypothesis is fairly strong in the 5-year village-level and 10-year province-level samples $(P$-value $<.05)$ and overwhelming in the 10 year village-level sample.

\section{Qualitative Findings}

I begin my detailed discussion by reviewing the qualitative patterns that emerge from the three-way logit estimation with the aid of table 3. 
For the purposes of the qualitative analysis, I classified coefficients with $t$-values greater than 1.645 in absolute value as being statistically significant and reported their signs. Observe the preponderance of significant coefficients in the case of the one-time move versus stay decision and their scarcity in the case of the frequent move versus one-time move decision. The motives for remigration appear to be the same as those for migration, to the degree that these decisions can be predicted by explanatory variables measured at the beginning of the period.

As repeatedly demonstrated in the migration literature, the likelihood of a move is seen to be inversely related to age and to duration of residence at beginning-of-the-period locality. Younger people face a longer time span over which the benefits from migration are to be reaped, hence they tend to be more mobile. The shorter the duration of stay in a particular locality, the less will be the individual's attachment to that locality, given the low level of investment in locationspecific capital. ${ }^{15}$ The schooling coefficient confirms the findings from other countries, which show that the better educated migrate more frequently. ${ }^{16}$ Increased mobility of individuals with higher educational attainment is presumably due to their ability to foresee and make use of diverse opportunities. There is some evidence that age and schooling affect the remigration probabilities in a similar fashion. ${ }^{17}$ Younger individuals are less likely to have accumulated location-specific capital and are therefore more likely to remigrate. Better-educated individuals have a larger human capital stock and can afford to have move-related immediate losses providing the rate of return in the final destination justifies it. They are more likely to engage in search in the national labor market and are in a better position to process information about job opportunities.

Undesirable conditions, like residence in a rural area-where job opportunities are scarce-lack of job-related security, and unemployment increase the probability of a move in the first migration equation. ${ }^{18}$ Residence in the northern regions of Turkey, where population pressure on arable land is most pronounced, has a similar effect. There is some evidence that residence in the metropolitan areas of Ankara, İstanbul, and İzmir makes relocation after an initial move unlikely. Since these cities constitute major absorption centers for migrants, they generally function as final destinations in stepwise migration processes (preconceived repeat moves). It could also be argued that those who leave the metropolitan areas of the three largest cities will have narrowed considerably their list of potential destinations and thereby decreased the probability of remigration.

With workers as the omitted category, occupational variables give some clues about an important dimension of the migration decision. Those who hold jobs that require skill (SKILL) are more mobile, while employers and the nonprofessional self-employed outside agriculture 


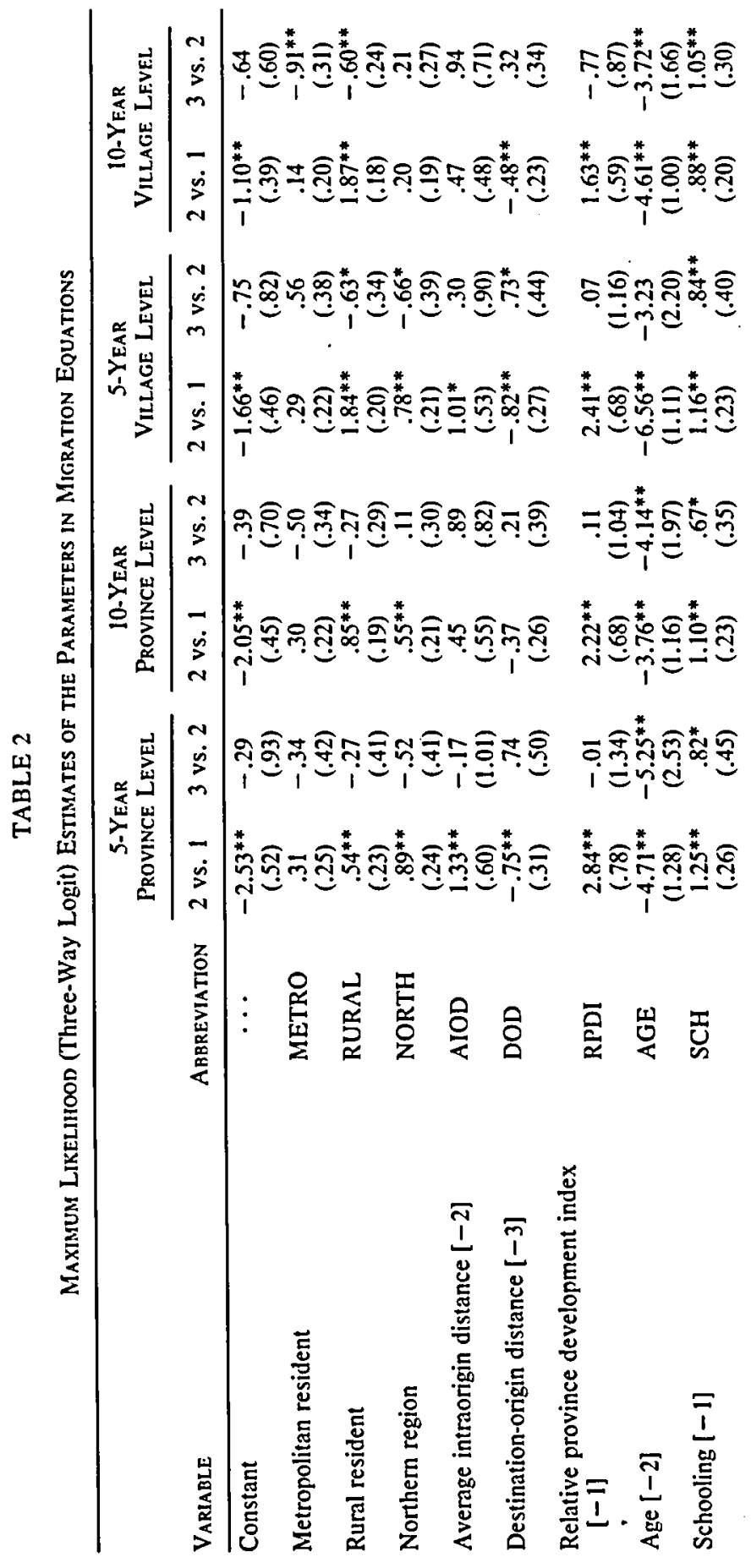




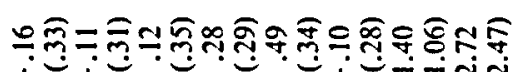

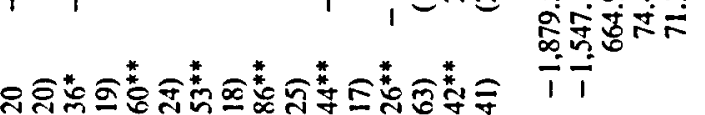

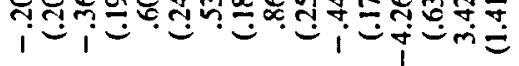

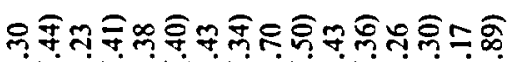

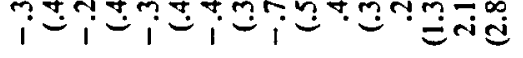

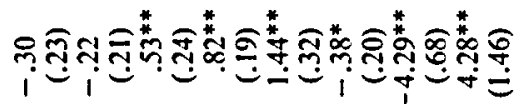

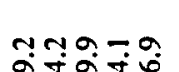

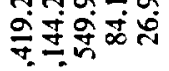

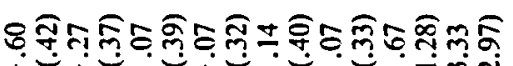

落

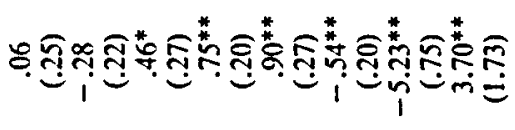

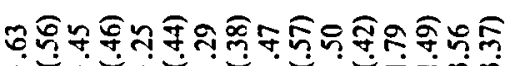

i.

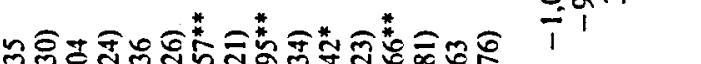

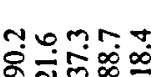

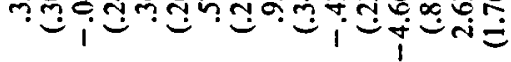

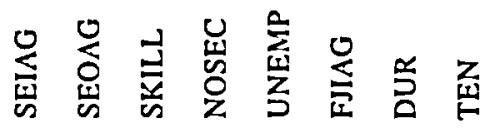

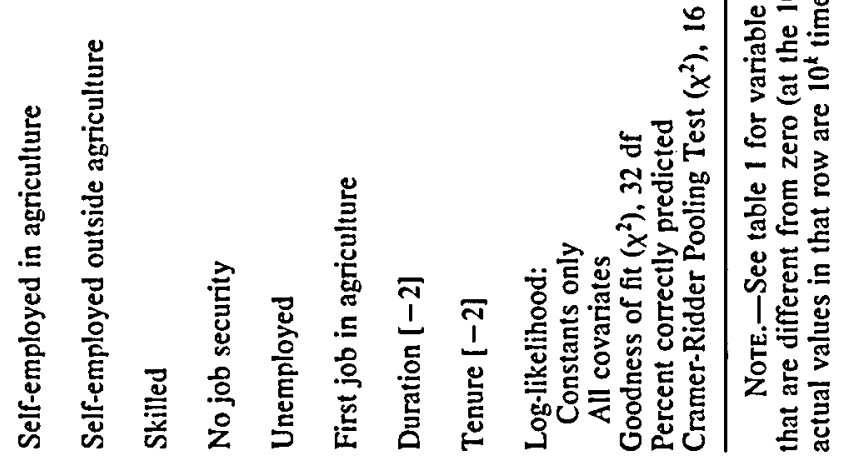




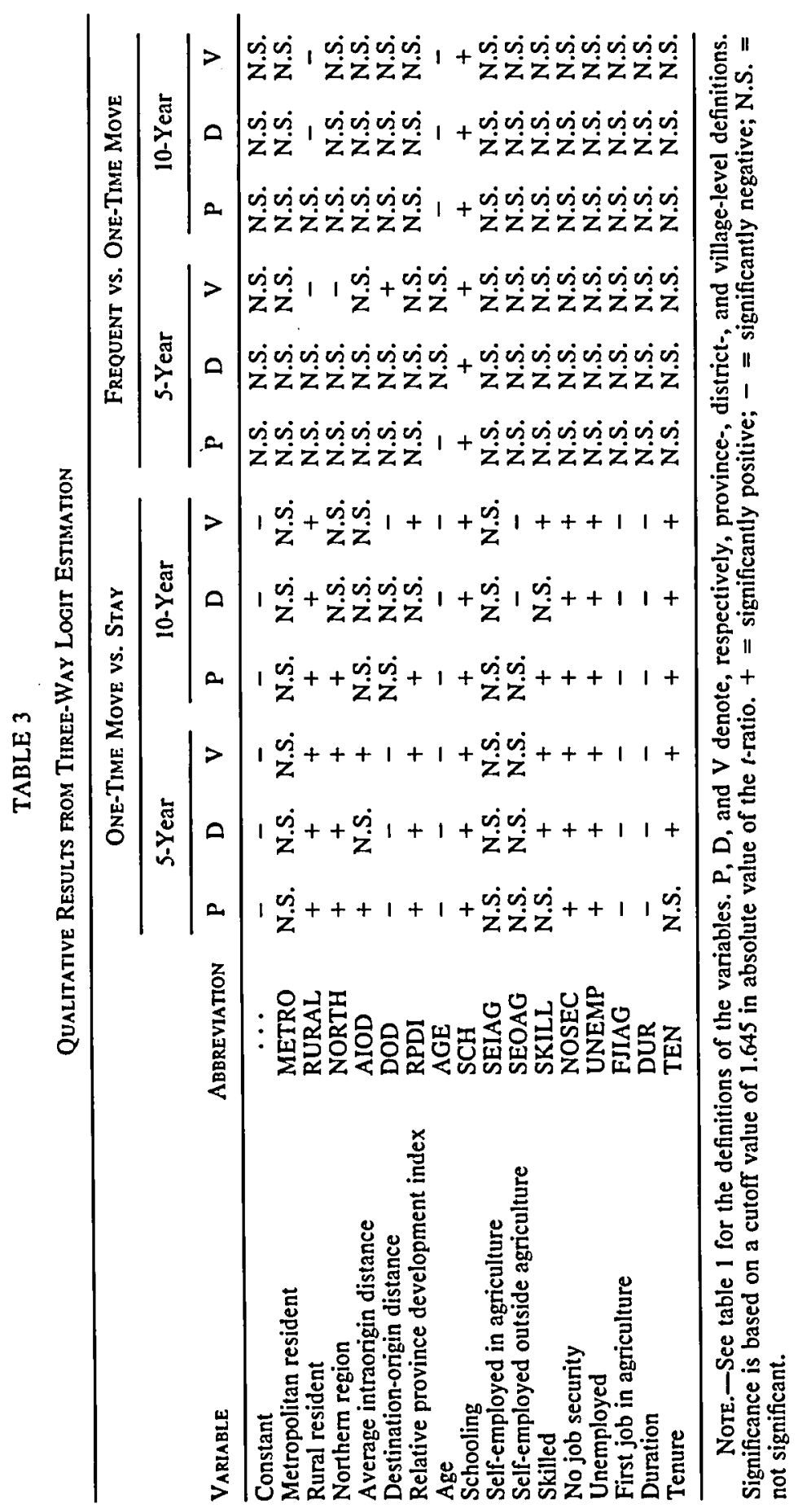


(SEOAG) tend to be less mobile. Evidently the high human capital component of the SKILL category's endowments allows for location change with relative ease, in pursuit of new and better opportunities. ${ }^{19}$ The SEOAG category, in contrast, may have accumulated physical and location-specific capital (e.g., clientele) that will decrease the inducement to move. We would expect self-employment in agriculture (SEIAG) to operate in a similar fashion, but the results suggest otherwise. Instead, it is entry into the labor market in the agricultural sector (FJIAG) that hinders the chances of relocation. The experience gained in agriculture usually has little transfer value, limiting the individual's opportunities elsewhere. Note that this variable is not measured at the beginning of the period but at the time of entry into the labor market. The individual may be holding a different job at the beginning of the period or, for that matter, may have moved. Nevertheless, entry to the labor force in agriculture continues to be a mobility-hindering characteristic.

We find that migration probabilities increase with tenure on the current or last job (TEN). One might find this counterintuitive, on grounds that accumulation of job-specific human capital is likely to make a move less likely. Note that this interpretation hinges on the premise that moves involve job separations. In our case, both the incidence of a job separation prior to the move (UNEMP) and the likelihood of a separation (NOSEC) are separately accounted for. The presence of these controls coupled with the nature of the data caution us against invoking the intuition mentioned above. In the HIPS survey, information on employment episodes was recorded only for jobs that lasted 6 months and more. The variable TEN was constructed by assuming that tenure accumulated regardless of location, providing that the three-digit occupation code, status, and sector of employment were the same. Thus it is closer to being a measure of general human capital than job-specific human capital. In the case of unemployed individuals, TEN was set equal to job tenure at the most recently held job. Since UNEMP is included as a regressor, this affords a consistent interpretation of TEN (labor market experience on the current or most recently held job) as a measure of the earnings potential of the individual. Thus the findings are consistent with the human capital model. ${ }^{20}$ The nature of the data suggest a second plausible interpretation. Promotions and job transfers were not treated as job changes in the HIPS survey. Obviously, there are moves that result from job transfers. Since employers would be more likely to transfer workers who have a considerable investment in the company, TEN could also be picking up the effect of the individual's knowledge of a job waiting at the destination locality. ${ }^{21}$

The construction of the distance variables utilized in the migration equations requires explanation. The destination-origin interprovince 
distance (DOD) was taken to be the highway distance (in kilometers) between the province center of the origin locality and the province center of the "most likely" destination, where the most likely destination was taken to be the province center that received the highest proportion of migrants from the origin province, based on the interprovince flows obtained from the 1960 and 1965 censuses. ${ }^{22}$ Thus DOD corresponds to a standard concept in the migration literature, and serves as an indicator of monetary, psychological, and information costs associated with the move. ${ }^{23}$ The average origin intraprovince distance (AIOD) was taken as the radius of a circle equal in area to one-half the planar surface area (in squared kilometers) of the origin province. My objective in using AIOD was to capture a factor similar to DOD, albeit at the level of intraprovince moves. ${ }^{24}$ Table 2 shows that indeed DOD has the expected negative effect in the first migration equation. In the case of AIOD, however, 5-year results counter the "cost" interpretation. It appears that there is a province-size effect, which increases the probability of migration.

The construction of the relative province development index (RPDI) also requires explanation. This variable was intended to be an aggregate measure of the degree of development (or appeal) of each province, capturing the macrolevel push and pull forces. It was constructed as a relative measure, by taking the ratio of the socioeconomic development index of the most likely potential destination to that of the province of origin. ${ }^{25}$ The positive coefficient on RPDI indicates that the macrolevel push and pull forces are indeed at work. For all but one of the definitions of migration, a high potential improvement in earnings as measured by the index at the province level renders a move more likely.

\section{Temporal and Spatial Dimensions of the Migration Decision}

Next 1 examine the changes in the influence of a given explanatory variable when different definitions of migration are invoked, using the three-way logit estimates reported in table 2 . Since district- and villagelevel results were very similar, the discussion is confined to the extreme spatial concepts. I begin by reviewing the patterns that emerge in going from the 5-year period to the 10-year period within a given locational specification (province and village). The contrast here is between a shorter and a longer decision period. In comparing the results for the 5-year (short-term) definitions with those for the 10-year (long-term) definitions, it should be kept in mind that the first begin with the year 1968, and the second begin with the year 1963. Most of the explanatory variables utilized are "period-dependent," in that their values depend on the choice of the beginning date for the period. Hence, the comparison is not only between a shorter-term response 
and a longer-term response, but also between the effects of variables from a later point in the individuals' life-cycles and the effects of those from an earlier point.

A quick glance at table 2 suggests that explanatory variables do not have an impact on migration in the same manner over the lifecycle. Perhaps more to the point, I found that interprovincial migration and remigration probabilities are more responsive to AGE in the short run. ${ }^{26}$ In the first migration equation, the coefficients of the distance variables, DOD and AIOD, the macrolevel push and pull variable RPDI and that of NORTH (residence in northern regions) all decrease in magnitude in going from the 5-year to the 10-year definitions. Even though RURAL (residence in rural areas) does not fit this pattern, a decreasing overall long-term importance of the macroeconomic forces relative to the personal characteristics of the individual is evident. The observation that the coefficients of the statistically significant occupational variables (SEOAG, SKILL, and FJIAG) are larger (in absolute value) at every locational specification in the long run supports this point. In the case of interprovincial moves, the results from DUR, TEN, and NOSEC reinforce this finding.

Individuals who are unemployed at the beginning of the period are more likely to move in the short run rather than in the long run. Unlike the occupational dummies, which capture more permanent traits of the individual, UNEMP captures membership in a transient state. If individuals exit that state, the likelihood of a move goes down considerably. In contrast, holding occupational membership and human capital stock constant, some individuals are more likely to be unemployed at a given point in time. According to this interpretation, UNEMP might capture an important dimension of heterogeneity not captured by the other variables. As a consequence, membership in the unemployed state at a point in time continues to have an impact on events that unfold later. The patterns with FJIAG and NOSEC corroborate the notion that employment experiences from earlier periods in the individuals' life-cycles continue to exert influence on their mobility decisions at later points.

Few discernible patterns emerge as we compare the village-level results to the province-level results within a given time framework (5-year and 10-year). The contrast here is between a narrower and a wider spatial concept; longer distances have to be traveled to move across a province boundary. We would therefore expect costs and uncertainty to figure in more forcefully when province-level migrations are brought under focus. The results with $\mathrm{AGE}$ and $\mathrm{SCH}$ are in line with this argument. Older, educated individuals are likely to be better in exercising judgment when faced with uncertainty. This gives them an edge in longer distance moves. We find that better-educated individ- 
uals are less likely to remigrate at the province level than at the village level, perhaps because they are less likely to make costly mistakes. Likewise the wisdom that comes with age manifests itself in the form of a smaller mitigating factor for province-level migrations and a larger mitigating factor for village-level remigrations.

There are other patterns that support the increased relevance of costs and risks when interprovincial moves are planned. Residents of rural areas, where information is likely to be relatively scarce, are more likely to undertake short-distance moves rather than longdistance moves. Residence in the northern regions (NORTH), in contrast, becomes less forceful in explaining village-level moves, compared with province-level moves. This corroborates the anecdotal evidence, which points at the longer-distance nature of migrations that starts in the northern part of the country. ${ }^{27}$ The cumulative experience with migration gives the sending communities in the north an important informational edge.

Finally, observe that UNEMP and NOSEC have larger villagelevel coefficients in the case of 5-year moves, and larger province-level coefficients in the case of 10-year moves. Negative experiences in the local labor market compel individuals to seek for nearby opportunities in the short run. Search is extended to more distant localities in the long run, as more information becomes available.

\section{Quantifying the Impact of the Variables}

A key finding that emerges from table 2 is that dummy variables like RURAL, NOSEC, and UNEMP have enormous influence on the migration decision, compared with multiple-valued explanatory variables such as AGE, DUR, and SCH. Incidence of unemployment (UNEMP), for example, has an impact on mobility equivalent to 8-12 years of schooling, depending on the definition of migration. Based on approximate calculations involving 5-year and 10-year coefficients of AGE, DUR, and TEN at the province level, it takes 8-16 years of residence in the same locality to offset the "push" forces operating in the rural areas, as captured by the coefficient of RURAL. Comparable figures at the village level are $28-34$ years. $^{28}$

Of the remaining dummy variables, FJIAG has a mobilityhindering impact equivalent to 10-14 years of age over the 10-year period. The METRO variable has a similar mobility-hindering impact during the second round of the decision, equivalent to 13 years of age at the province level and 20 years of age at the village level over the 10 -year period. Also having a sizable influence is NORTH, especially at the province level.

Next, consider the impact of unemployment on the 5-year province-level move probability. Taking an employed individual as our ref- 
erence, we can calculate the impact of job loss as an augmentation in the odds of moving once relative to staying by the amount $2.59 .{ }^{29}$ That is, an unemployed individual would be about 2.6 times as likely to move once (rather than stay) compared with an employed individual. To illustrate the impact of NOSEC, consider switching an individual with no job-related security to a new job with security. The odds of a one-time move relative to the stay option would be reduced by the factor 0.57 . That is, having job-security would reduce the inducement to move by roughly one-half.

A similar exercise involving the macrolevel push and pull variable (RPDI) reveals the importance of regional imbalances in inducing migration flows. Consider relocating an individual who resides in Izmir, the third largest city (ranked third according to the aggregate index in B. Tolan's study from which RPDI has been calculated) to Isparta, an inland city in the southwestern part of the country (ranked twentyseventh in Tolan's study). ${ }^{30}$ The most likely destination for both provinces is Istanbul, 603 highway kilometers away from both province centers. The RPDI value for Isparta is 3.33 , more than twice that of Izmir, which is 1.51. Consider an individual who is at risk of moving across province boundaries over the 5-year period. Relocating the individual in Isparta would augment the odds of a one-time move relative to staying by the factor 1.68 . Since all but one of the 17 provinces in the eastern region (see fig. 1) had RPDI values below that of Isparta, the contribution of regional inequalities in generating migration flows is illustrated by this exercise.

To illustrate the impact of the distance variables, first note the AIOD variable in the first equation. Consider relocating an individual who resides in Uşak to Konya. I chose those cities because both have Izmir as their most likely destination and both have approximately equal values of RPDI (2.44 and 2.51, respectively). Uşak has one of the smallest AIOD values (29 kilometers), and Konya has the largest (89 kilometers). Again, taking an individual who is at risk of moving across province boundaries over the 5 -year period, the relocation working through AIOD would increase the odds of a one-time move relative to staying by 2.22 , or roughly twofold. Since Konya is more distant from İzmir (570 highway kilometers vs. 225 for Uşak), the effect of AIOD will be countered by the move-hindering effect of DOD, which equals 0.77 . Hence the net effect of having a large province such as Konya as the origin instead of a small one such as Uşak would be an increase by a factor of $2.22 \times 0.77 \cong 1.71$ in the odds.

Next, consider the effect of DOD in the first equation, using the 5 -year province-level estimates. Now consider relocating an individual who resides in Edirne to Elazıg. For both provinces İstanbul is the most likely destination and both have identical RPDI values. The high- 
way distance between the respective province centers and İstanbul is 1,222 kilometers in the case of Elazıg and 235 kilometers in the case of Edirne. Ignoring the negligible difference in the AIOD values, the odds of a one-time move relative to staying would be reduced by the factor $0.48 .^{31}$

Finally, look at the occupational category dummies, SEOAG, SKILL, and SEIAG. Switching an individual from the SKILL category to the SEOAG category, for example, would decrease the odds of a one-time move relative to staying by a factor of 0.48 using the 10 -year province-level estimates and 0.38 using the 10-year villagelevel estimates. Starting out in agriculture (FJIAG) will decrease the odds of a one-time move relative to staying by a factor of 0.66 at the 5 -year province level and 0.58 at the 10 -year province level.

\section{Repeat versus Return Migration Distinction}

The final issue $I$ address is whether the determinants of remigration are different when repeat and return moves are examined separately. The theoretical formulation adopted here offers useful predictions for distinguishing repeat and return movers. When rates of return are treated as random variables, it makes sense to assume that individuals are better informed about localities where they previously resided. This indicates that risk-averse frequent migrants will tend to prefer return moves, unless employment conditions at the origin render that strategy futile. From a human capital perspective, individuals who have longer time horizons or larger investments in human capital are in a better position to take risks, so they will be more likely to engage in repeat moves. Individuals who have a significant location-specific component in their human capital, however, will prefer to return. ${ }^{32}$

To minimize inferential problems due to small cells, I confined my empirical investigation to the 10 -year samples. The four-way logit estimates are reported in table 4, where stayers serve as the reference category throughout. The estimated equations are highly significant according to the usual goodness of fit criterion. Between $74 \%$ and $82 \%$ of the actual migration outcomes are correctly predicted. As with the three-way models, the frequency of incorrect predictions increases as the definition of migration is widened. In all three samples, the Cramer-Ridder Pooling Test overwhelmingly rejects the null hypothesis that repeaters and returners can be treated as a single group. The estimates for one-time movers change negligibly when I further break down the frequent-mover category. When the focus is on a given migrant category, I find that the explanatory variables typically operate in the same qualitative manner at the province, district, and village levels. Exceptions to this pattern take the form of nonsignificant coefficients rather than sign reversals. In some cases, district-level coeffi- 
cients resemble province-level coefficients in magnitude; in other cases they resemble village-level coefficients.

The results lend support to the human capital arguments. Bettereducated individuals, especially those with specialization (SKILL), are more likely to engage in repeat moves in search of higher returns. As individuals age, they shy away from engaging in new adventures; the return option becomes more attractive relative to the repeat option. Employment conditions in the origin locality play a very significant role: while unemployed individuals prefer to move on, employed individuals without job security tend to return. The likelihood of a return despite lack of job security is largest in the case of village-level moves, which are the cheapest moves to finance.

There is evidence that the presence of location-specific capital favors return moves. Self-employed migrants outside agriculture are highly unlikely to engage in longer distance repeat moves. Those who started out in agriculture display a similar aversion at all levels of analysis. In contrast, self-employment in agriculture at a later time, namely, at the time the migration decision is made, does not play a role in the outcome. This is attributable to the fact that individuals who engage in agriculture early on are likely to have larger investments in it.

Estimates of the duration effects provide confirmation of the role of first-hand information. Note that the magnitude of the coefficient on DUR is largest for repeaters and smallest for returners (in absolute value). An increase in the length of residence hinders mobility but increases the likelihood of a return move conditional on a move taking place. We find that 10 years of residence in the origin location increases the odds of a return move relative to a repeat move by the factor of 1.63 in the case of interprovincial moves. This factor is about 1.36 and 1.26 in the case of intraprovincial moves, suggesting that affinity with the conditions in the origin is more valuable when long distance moves are involved.

Findings from regional variables offer further verification of the anecdotal evidence concerning migrations in Turkey. Residence in northern Turkey (NORTH) makes repeat moves, rather than return moves, more likely. This is especially true when long distance moves are involved. Coefficient estimates on AIOD suggest that individuals who start out in large provinces engage in stepwise migrations. This is in agreement with the well-documented pattern of a first move to a district or province center, followed by a long distance move. ${ }^{33}$ The larger the province, the more diffuse is the information about potential final destinations. Risk-averse individuals might prefer to spend time in intermediate locations before committing themselves to a more costly move. 


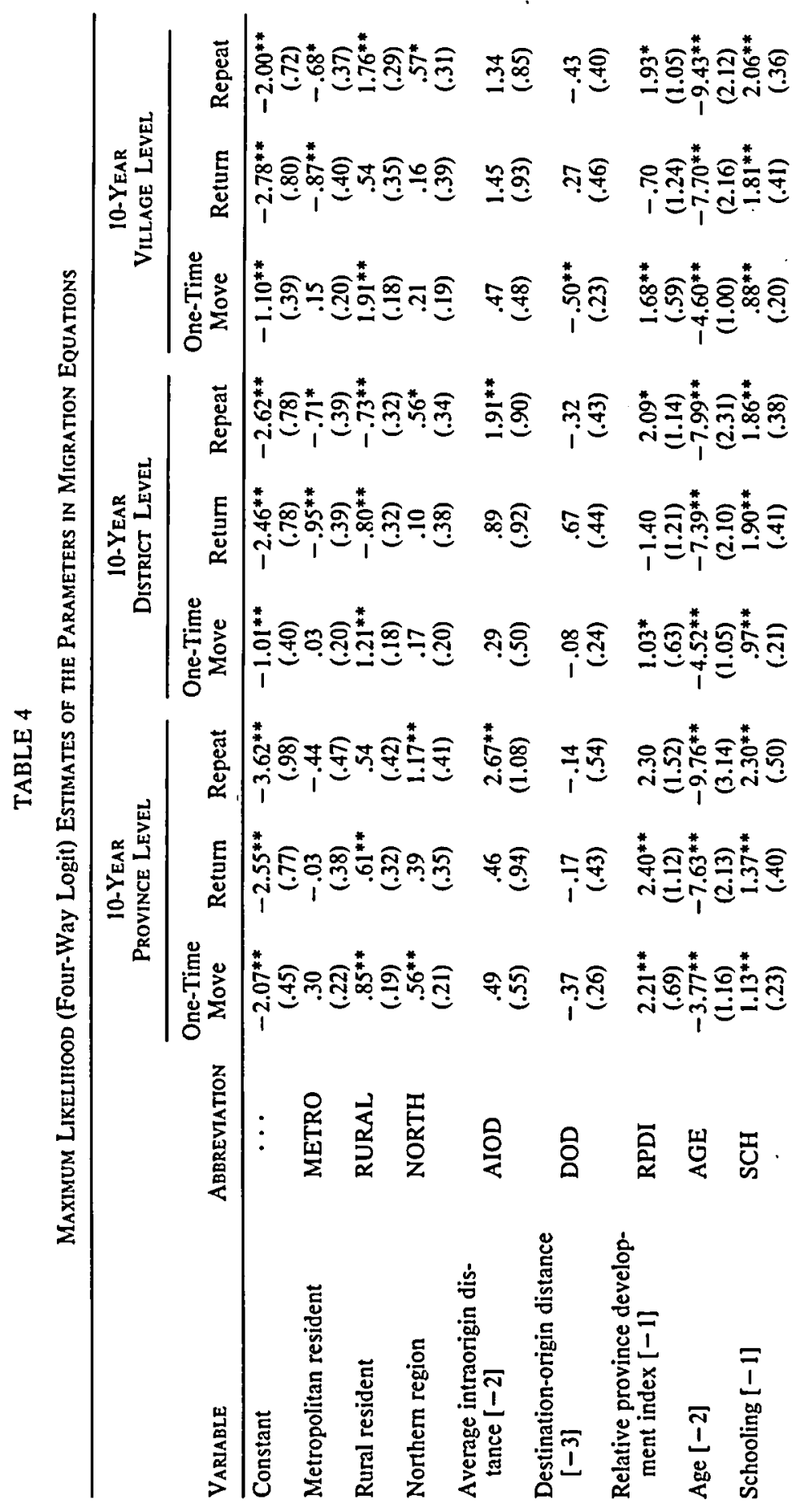




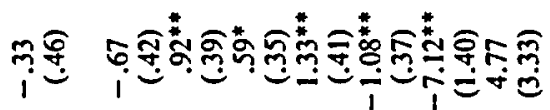

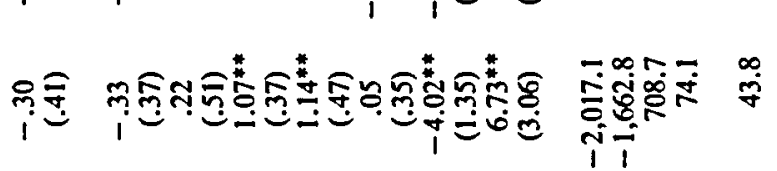

东商

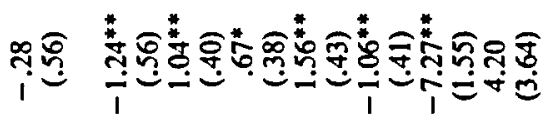

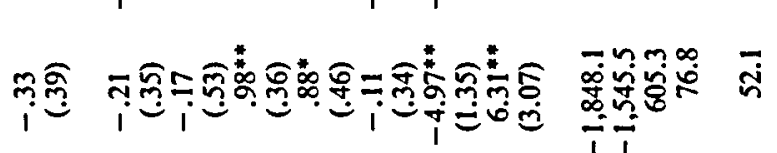

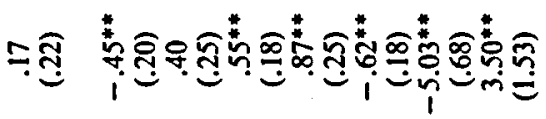

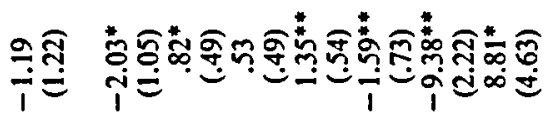

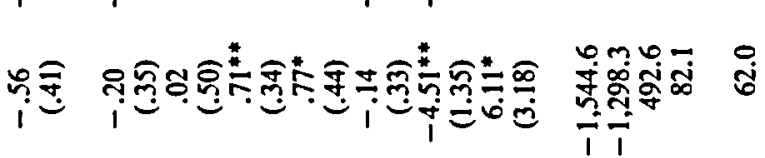

๖. ํㅓ

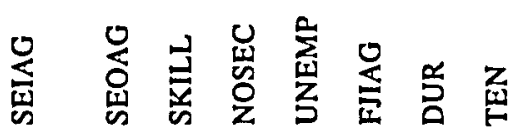

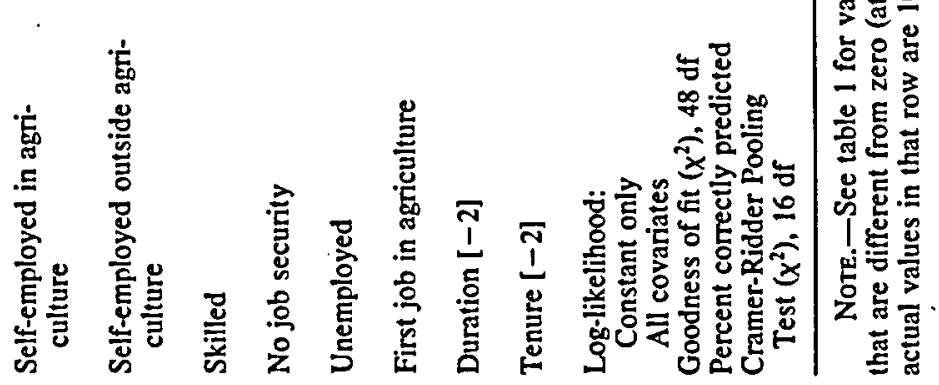


Coefficient estimates on RURAL and METRO offer additional evidence on stepwise migrations. We find that frequent migrants from rural areas are more likely to be repeaters rather than returners when they move within their district; the differences are statistically insignificant at other levels. Frequent migrants who start out in the metropolitan areas of the three largest cities and engage in intraprovincial moves also opt for repeat moves. These patterns corroborate the resettlement patterns described in studies of migrant communities. Firsttime migrants typically join relatives who had moved earlier to the destination locality. After making the initial adjustments and finding jobs, they seek better accommodations and resettle. ${ }^{34}$ Coefficients on RPDI offer evidence that intraprovincial stepwise migrations originate in backward regions.

While the results on TEN provide further validation of the role played by human capital, they also suggest that the link is complex. Province-level results indicate that individuals with long job tenure are much more likely to repeat rather than return. Thus job experience operates just like schooling and specialized skills. When we focus on intraprovincial moves, however, the return option dominates. The explanation for this reversal is likely to be found in the complex manner in which years of experience interacts with the form and quality of the original investment in human capital.

\section{Conclusions}

In this article, data on individual migration histories from 1963 to 1973 in Turkey were used to determine the qualitative and quantitative importance of the various factors behind migration and remigration. I adopted the economic-theoretic premise of the human capital and jobsearch tradition, which views geographic mobility as a response to differential earnings opportunities distributed over time and across space. Using a discrete choice formulation, the migration decision that sets the movers apart from the stayers and the remigration decision that sets apart the frequent (multiple) movers from the one-time movers were investigated. In an attempt to identify the relative importance of the various factors in generating different types of moves, I relied on six different definitions of migration. The qualitative findings were in line with those documented in the literature.

To quantify the impact of the explanatory variables on different types of moves, some of the more pronounced tendencies were examined further. This exercise revealed that undesirable labor market conditions such as residence in a rural area-where job opportunities are extremely limited-lack of job-related security, and unemployment had an enormous influence on the migration decision, compared with the human capital variables. A main conclusion that emerges from these comparisons and more elaborate counterfactuals is that the re- 
gional and macroeconomic effects that have been documented in the aggregate studies of migration flows in Turkey appear to hold up when individual heterogeneity is controlled for. The profound impact of these variables can be reversed by policy intervention directed at the human capital variables only if rather extreme changes can be induced. It seems that attempts to influence migration flows will work better if policies are designed to alter broad regional economic structures. This is not to say that the usual human capital concerns (e.g., the emphasis on education or training) are misplaced-obviously these have a bearing on the individual labor market outcomes. However, unless the interactions between the two levels are properly understood, interventions targeting the individual may fall short of the policy goals.

A second conclusion that emerges from the comparisons is that the findings are rather sensitive to the definition of migration. The examination of the relative importance of the various forces over the shorter (5-year) and longer (10-year) decision period was especially revealing in this regard. It showed that the influence of initial macroeconomic forces decreased over time, relative to the specific conditions the individuals faced in the labor market. There was evidence, however, that background variables (schooling, having started work in agriculture) continued to exert influence on mobility at later periods. I found that residence in the northern region of the country, where population pressure on land is most pronounced, had a larger impact on decisions involving longer distance moves.

A third, and possibly the most important, conclusion is that repeat-return distinction is crucial to the proper understanding of the migration phenomenon. Without that distinction it was difficult to distinguish the motivating factors behind migration and remigration, using the explanatory variables measured at the beginning of the period. Once remigrants were broken down further as repeat and return migrants, empirical counterparts of the theoretical constructs such as human capital, location-specific capital, imperfect information, costs, and so on provided significantly sharper results.

\section{Appendix}

Statistical Methods

The logit probabilities for cell membership are

$$
P_{d}=\frac{\exp \left(\alpha_{d}^{\prime} \mathrm{x}\right)}{\sum_{k=\mathrm{s}, \mathrm{o}, \mathrm{f}} \exp \left(\alpha_{k}^{\prime} \mathrm{x}\right)}, d=\mathrm{s}, \mathrm{o}, \mathrm{f},
$$

where $\mathbf{x}$ denotes the vector of explanatory variables, $\alpha$ 's denote parameters to be estimated, and the subscripts refer to the stay (s), one-time move (o), 
and frequent move (f) options. It is straightforward to show that

$$
\begin{aligned}
& P_{\mathrm{o}} / P_{\mathrm{s}}=\exp \left[\left(\alpha_{\mathrm{o}}-\alpha_{\mathrm{s}}\right)^{\prime} \mathrm{x}\right]=\exp \left(\beta_{\mathrm{i}}^{\prime} \mathrm{x}\right), \\
& P_{\mathrm{f}} / P_{\mathrm{o}}=\exp \left[\left(\alpha_{\mathrm{f}}-\alpha_{\mathrm{o}}\right)^{\prime} \mathrm{x}\right]=\exp \left(\beta_{2}^{\prime} \mathrm{x}\right),
\end{aligned}
$$

which establishes the connection between the structural and reduced form parameters. Note that at most two of the three structural parameter vectors can be identified. In the empirical work, I set $\alpha_{3}=0$.

While MLM is very attractive from a computational point of view, it has a major drawback. The choice probabilities satisfy the Independence of Irrelevant Alternatives (IIA) property, whereby the choice between any two alternatives is independent of the third. In our context, while the MLM set-up offers a natural way of capturing the decision rule represented by (6) and (7), it ignores the interdependence between the migration and remigration decisions. Elsewhere I tested the independence assumption using a simultaneous probit formulation, and found strong evidence in favor of independence. ${ }^{35}$ To be able to use the probit formulation, I had to modify the decision rule. Specifically, the case $r^{*}=y_{1}^{*}+y_{2}^{*}>0>y_{1}^{*}$ (which would imply the optimality of the frequent move option) was treated as a stay decision. The modification is harmless if anticipated earnings from each move in a sequence exceed the anticipated costs of that move. This condition rules out the case of the frequent move being optimal, when the best one-time move policy is dominated by the stay policy. The nonmodified version of the problem turned out to be computationally intractable.

Since the migration equations are of the logit type, the direct partial derivative interpretation of the coefficients does not apply. The partial effect of a unit change in the value of an explanatory variable on the outcome is given by the product of its coefficient and the logistic density, which will vary according to the point of evaluation. While the calculation of the estimated partial derivative of the probability with respect to an explanatory variable is straightforward, a simpler and more appealing alternative is available. Because logit probabilities are log-linear functions of the explanatory variables and parameters, they can be put into relative odds form with ease. The utility of this form should be apparent in the reduced form expressions (A2) and (A3), which give the odds of a one-time move relative to staying and the odds of a frequent move relative to a one-time move, respectively. Reintroducing the individual subscripts, the contrast between individuals $i$ and $j$ may be examined using expressions of the form

$$
\frac{P_{\mathrm{o}}\left(\mathrm{x}_{i}\right) / P_{\mathrm{s}}\left(\mathrm{x}_{i}\right)}{P_{\mathrm{o}}\left(\mathrm{x}_{\mathrm{j}}\right) / P_{\mathrm{s}}\left(\mathrm{x}_{j}\right)}=\exp \left[\beta_{1}^{\prime}\left(\mathrm{x}_{i}-\mathrm{x}_{j}\right)\right],
$$

where the probabilities have been written as explicit functions of $\mathbf{x}$. Instead, suppose we were to focus on a given individual and consider the impact of a change in the $k$ th element of $x$ by the amount $\Delta x_{k}$. Using (A4), we obtain

$$
\frac{P_{\mathrm{o}}\left(\mathrm{x}+\Delta \mathrm{x}_{k}\right) / P_{\mathrm{s}}\left(\mathrm{x}+\Delta \mathrm{x}_{k}\right)}{P_{\mathrm{o}}(\mathrm{x}) / P_{\mathrm{s}}(\mathrm{x})}=\exp \left[\beta_{1 k} \Delta \mathrm{x}_{k}\right]
$$


Thus, the proportionate change in the relative odds (say, of a one-time move rather than no move) induced by a given change in the value of an explanatory variable may be calculated as in (AS), using the relevant parameter estimate.

In interpreting the findings from the four-way logit analysis, it is tempting to carry out the repeat and return contrast conditional on remigration. While the probability of a repeat move conditional on remigration $\boldsymbol{P}_{\mathrm{f}} /\left(\boldsymbol{P}_{\mathrm{fr}}+\boldsymbol{P}_{\mathrm{fb}}\right)$ yields a computationally unattractive form, the relative odds form is easily calculated as

$$
\frac{P_{\mathrm{ff}} /\left(P_{\mathrm{ff}}+P_{\mathrm{fb}}\right)}{P_{\mathrm{fb}} /\left(P_{\mathrm{ff}}+P_{\mathrm{fb}}\right)}=\frac{P_{\mathrm{ff}}}{P_{\mathrm{fb}}}=\exp \left[\left(\beta_{2 \mathrm{f}}-\beta_{2 \mathrm{~b}}\right)^{\prime} \mathrm{x}\right]
$$

from knowledge of the (reduced-form) parameter estimates $\beta_{2 f}$ and $\beta_{2 b}$ of repeat and return-migration equations. Note, however, that the same expression is obtained if the probability of another alternative (say, $P_{s}$ ) is used in place of $\left(P_{\mathrm{ff}}+P_{\mathrm{fb}}\right)$. This is a consequence of the IIA property. 


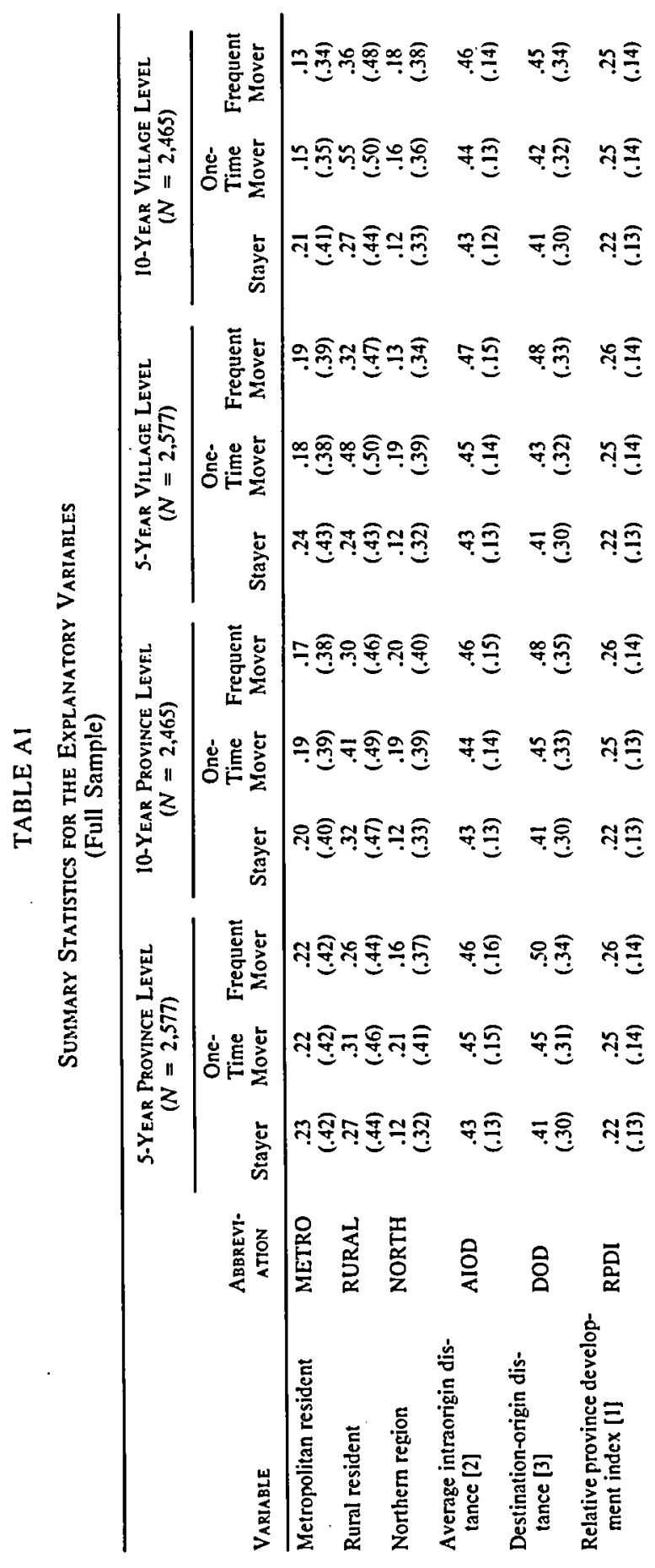




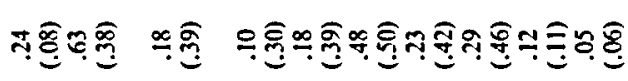

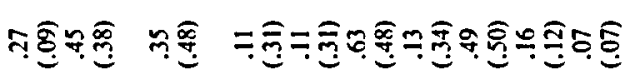

空

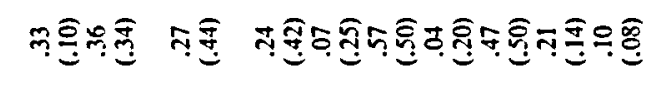

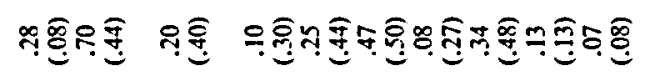

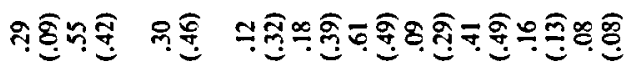

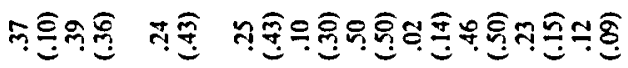

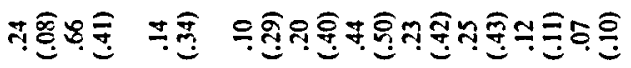

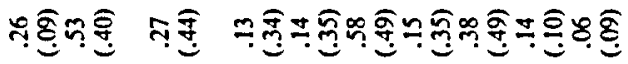

\&

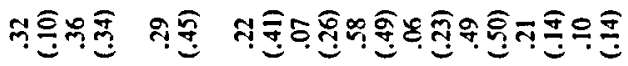

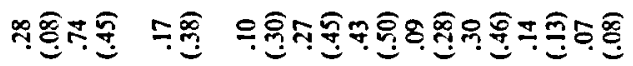

$\bar{\infty}$

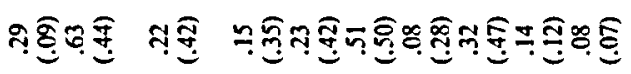

$\frac{\pi}{4}$

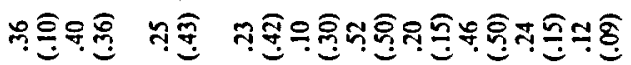

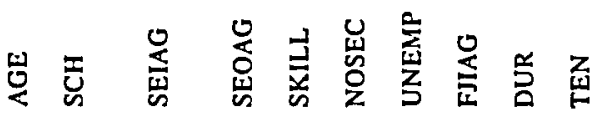




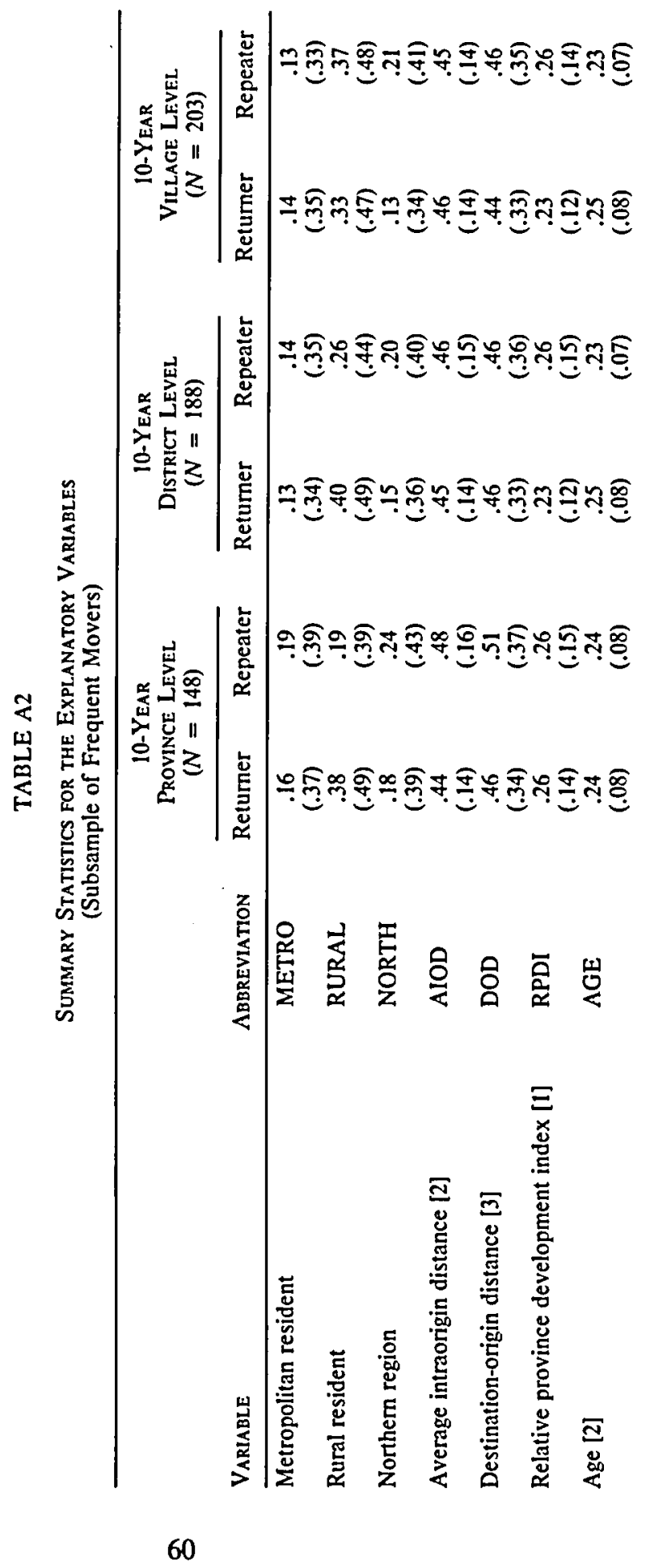




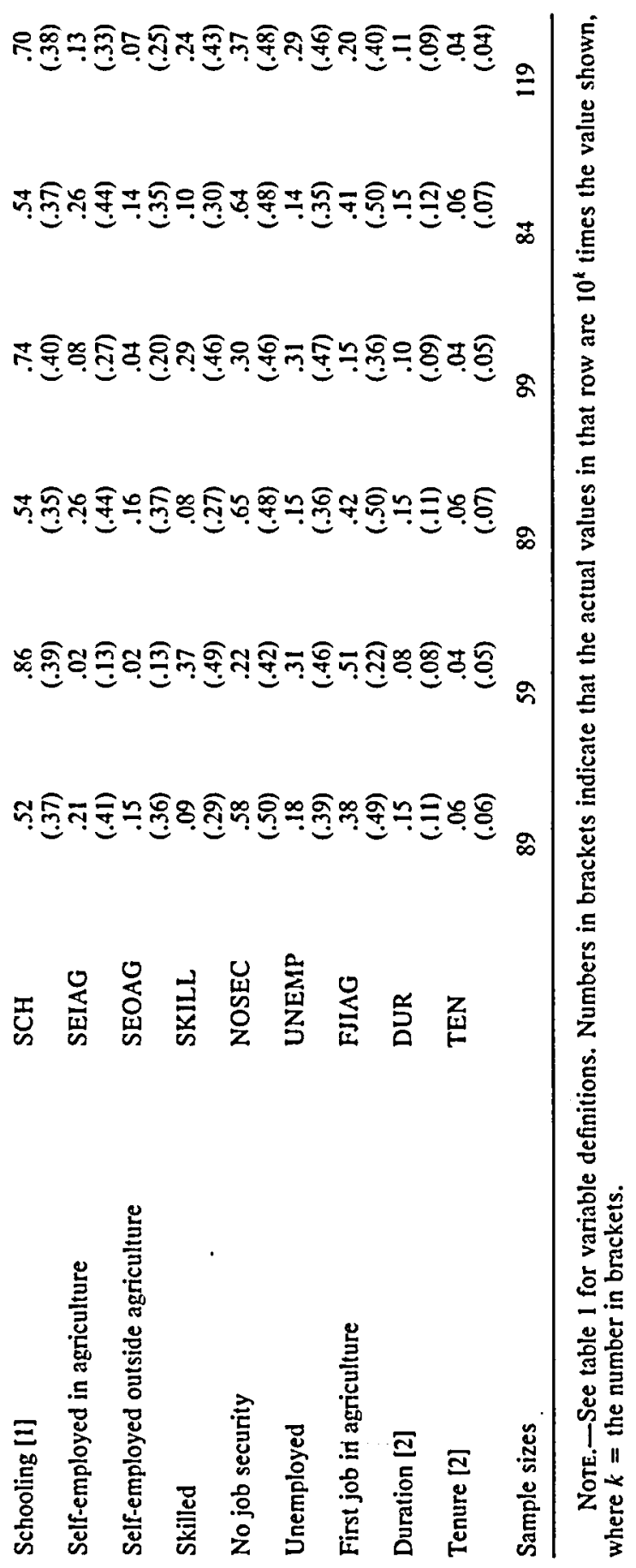

61 
Notes

* This research was funded in part by grant number 1 RO1 HD23321-01 from the National Institute of Child Health and Human Development (NICHD). Additional support from the NICHD through the Population Research Center and the Economics Research Center at the University of Chicago is gratefully acknowledged. Special thanks are due to the director and staff of Hacettepe Institute of Population Studies, Ankara, Turkey, for providing me with access to the raw data from its 1973 survey. Throughout the project I received enthusiastic input and feedback from Arthur S. Goldberger, George Jakubson, Ken Snowden, and Jeffrey G. Williamson. Comments and criticisms of Charles Hirchmann, Andrew Morrison, Jonathan Pritchett, and workshop participants at Cornell University and the University of Chicago, and two anonymous referees were extremely useful in shaping the current version of the article. Dae Chang Lee, Sudip Thakor, and Zhong Gao provided research assistance and Paulette Carlisle and Vicki Spencer provided typing assistance. An earlier version of this article was circulated rnder the title "Migration and Remigration in Turkey: Micro-Econometric Evidence from 1963-1973," as Department of Economics Working Paper no. 409, Cornell University (June 1988).

1. See S. K. Kartal, Ekonomik ve Sosyal Yönleriyle Kentlileşme (Social dimensions of urbanization in Turkey) (Ankara: Yurt Yayınları, 1983), p. 21. Various aspects of this process are addressed in P. E. Benedict, E. Tümertekin, and F. Mansur, eds., Turkey: Geographic and Social Perspectives (Leiden: Brill, 1974); S. Cerit, "Türkiye'de İller Arası Göçler, 1950-1980" (Interprovincial migrations in Turkey, 1950-1980), Nïfusbilim Dergisi 8 (1986): 81-103; M. N. Danielson and R. Keleş, "Urbanization and Income Distribution in Turkey," in The Political Economy of Income Distribution in Turkey, ed. E. Özbudun and A. Ulusan (New York: Holmes \& Meier, 1980), pp. 269-309; A. Gedik, "A Causal Analysis of the Destination Choice of Village to Province-Center Migrants in Turkey, 1965-70" (Ph.D. thesis, University of Washington, 1977), and "Rural to Urban versus Urban to Urban Migration in Turkey," Espace, Populations, Societies 1 (1985): 86-92; K. H. Karpat, The Gecekondu: Rural Migration and Urbanization (Cambridge: Cambridge University Press, 1976); R. Keleş, "Türkiye'de Şehirleşme Eğilimleri" (Urbanization trends in Turkey), Siyasal Bilgiler Fakültesi Dergisi 25 (1970): 41-83, and Urbanization in Turkey (New York: Ford Foundation, 1972); T. Kuran, "Internal Migration: The Unorganized Urban Sector and Income Distribution in Turkey, 1963-1973," in Özbudun and Ulusan, eds.; N. Levine, "Old Culture-New Culture: A Study of Migrants in Ankara, Turkey," Social Forces 51 (March 1972): 355-68; S. S. Lieberman, An Economic Approach to Differential Demographic Behavior in Turkey (New York: Garland, 1979); J. M. Munro, "Migration in Turkey," Economic Development and Cultural Change 22 (July 1974): 634-53; K. Tanfer, "Internal Migration in Turkey: Socioeconomic Characteristics by Destination and Type of Move, 1965-70," Studies in Comparative International Development 17 (Spring 1983): 76-111; B. Tekçe, "Urbanization and Migration in Turkey" (Ph.D. thesis, Princeton University, 1975); 1. Tekeli and L. Erder, Yerlesme Yapısının Uyum Sïreci Olarak $I_{\zeta}$ Göçler (Internal migrations as the adjustment process of the settlement structure) (Ankara: Hacettepe Universitesi Yayınları, 1978), and "Settlement Distribution and Structural Change in Turkish Agriculture: A Key to Migration Models and Policy," in Why People Move: Comparative Perspectives on the Dynamics of Internal Migration, ed. J. Balan (Paris: Unesco, 1981), pp. 122-39; E. Tümertekin, Urbanization and Urban Functions in Turkey (İstanbul: İstanbul University Faculty of Letters Press, 1973); S. Yener, 
1965-1970 Döneminde Iller Arası Göçler ve Gö̧ Edenlerin Nitelikleri (Interprovincial moves during the $1965-70$ period and the characteristics of the migrants) (Ankara: T. C. Başbakanlık Devlet Planlama Teşkilatı, 1977).

2. See Keleş, "Türkiye'de Şehirleşme Eğilimleri," p. 45; Munro, pp. 640-41; and M. D. Rivkin, Area Development for National Growth: The Turkish Precedent (New York: Praeger, 1965), pp. 215-16.

3 . Unless stated otherwise, the numbers quoted in this section are from the yearbooks published by Devlet Istatistik Enstitüsü (State Institute of Statistics).

4. World Bank, Turkey: Policies and Prospects for Growth (Washington, D.C.: World Bank, 1986), p. 241.

5. The Harris-Todaro model, which treats migration as a rational response to expected real wage differentials, reigns as the most influential work to date. See M. P. Todaro, "A Model of Labor Migration and Urban Unemployment in Less Developed Countries," American Economic Review 59 (March 1959): 138-48; and J. Harris and M. P. Todaro, "Migration, Unemployment, and Development: A Two-Sector Analysis," American Economic Review 60 (March 1970): 126-42. This model exploits the idea of dualism and focuses on aggregate flows, mainly of the rural-to-urban variety. The need to explain moves that counter the dominant flow requires modifications in the HarrisTodaro model. A frequently employed formalization combines Sjaastad's human capital model of migration with Mortensen and McCall's job-search formulation to provide the microfoundation. The classic papers are L. A. Sjaastad, "The Costs and Returns of Human Migration," Journal of Political Economy 70 (October 1962): 80-93; D. T. Mortensen, "Job Search, the Duration of Unemployment, and the Phillips Curve," American Economic Review 60 (December 1970): 847-61; and J. J. McCall, "Economics of Information and Job Search," Quarterly Journal of Economics 84 (February 1970): 113-26. A very readable synthesis may be found in J. Rothenberg, "On the Microcconomics of Internal Migration," in Internal Migration: A Comprehensive Perspective, ed. A. A. Brown and E. Neuberger (New York: Academic Press, 1977), pp. 183-205.

6. Models that formally incorporate the role of uncertainty into the analysis of migration include those by B. P. McCall and J. J. McCall, "A Sequential Study of Migration and Job Search," Journal of Labor Economics 5 (October 1987): 452-76; C. Pessino, "Sequential Migration Theory and Evidence from Peru," Journal of Development Economics 36 (July 1991): 55-87; and T. Vishwanath, "Information Flow, Job Search, and Migration," Journal of Development Economics 36 (July 1991): 313-35.

7. Elaborations on this model allow locational amenities to influence the migration decision. See P. E. Graves and P. D. Linneman, "Household Migration: Theoretical and Empirical Results," Journal of Urban Economics 6 (July 1979): 383-404; P. E. Graves, "Migration and Climate," Journal of Regional Science 20 (May 1980): 227-37, and "Migration with a Composite Amenity: The Role of Rents," Journal of Regional Science 23 (November 1983): 541-46; J. Roback, "Wages, Rents, and the Quality of Life," Journal of Political Economy 90 (December 1982): 1257-78.

8. For evidence in favor of this characterization, see A. M. J. Yezer and L. Thurston, "Migration Patterns and Income Change: Implication for the Human Capital Approach to Migration," Southern Economic Journal 43 (April 1976): 693-702; J. Allen, "Information and Subsequent Migration: Further Analysis and Additional Evidence," Southern Economic Journal 45 (April 1979): 1274-84; J. Da Vanzo, "Repeat Migration, Information Costs, and Location-Specific Capital," Population and Environment 4 (Spring 1981): 45- 
73; J. Da Vanzo and P. A. Morrison, "Return and Other Sequences of Migration in the United States," Demography 18 (February 1981): 85-101; H. W. Herzog and A. M. Schlottmann, "Migrant Information, Job Search and the Remigration Decision," Southern Economic Journal 50 (July 1983): 43-56; J. Da Vanzo, "Repeat Migration in the United States: Who Moves Back and Who Moves On?" Review of Economics and Statistics 65 (November 1983): 552-59; and Pessino.

9. J. S. Cramer and G. Ridder, "Pooling States in the Multinomial Logit Model," Journal of Econometrics 47 (February/March 1991): 267-72.

10. Intercepts must be left unconstrained because the proportion of repeaters in a given sample may not be the same as the proportion of returners.

11. These intervals were selected largely as a matter of convenience. One of the project objectives was the examination of the links between the migration decision and the earnings outcome (See 1. Tunal,, "A General Structure for Models of Double Selection and an Application to a Joint Migration/Earnings Process with Remigration," in Research in Labor Economics, ed. R. Ehrenberg [Greenwich, Conn.: JAI, 1986], vol. 8, pt. B:235-282.) Since income data were available only for 1973 , there was no room for flexibility in picking the end point of the migration intervals.

12. The evidence compiled by P. Brigg, "Some Economic Interpretations of Case Studies of Urban Migration in Developing Countries," IBRD Working Paper No. 217 (International Bank for Reconstruction and Development, Washington, D.C., 1973) from 27 field surveys of urban and rural communities in Africa, Asia, and Latin America indicates that, while factors such as "seeking education opportunities" and "accompanying family members" occasionally show up as primary reasons, economic motives predominate migration. This also emerges from an earlier survey conducted in Turkey (Vital Statistics from the Turkish Demographic Survey, 1966-67 [Ankara: Ministry of Health and Social Welfare, 1970]), especially when males are considered. In the HIPS sample with which I worked, moves triggered by an educational motive could be identified. Such moves were very rare, mainly because the survey was administered to males who were 18 and older. Since none of these individuals was a household head, they were not included in the working samples. Moves triggered by family considerations could not be detected. This is not to deny the importance of such considerations in a broader context; see, e.g., O. Stark and R. E. B. Lucas, "Migration, Remittances, and the Family," Economic Development and Cultural Change 36 (April 1988): 465-81; M. R. Rosenzweig and O. Stark, "Consumption Smoothing, Migration and Marriage: Evidence from India," Journal of Political Economy 97 (August 1989): 905-26; G. M. Shields and M. P. Shields, "Family Migration and Nonmarket Activities in Costa Rica," Economic Development and Cultural Change 38 (October 1989): 73-88.

13. Historically, the bulk of international migration has taken the form of tightly regulated flows, controlled by government agencies in the sending as well as the receiving country. Apart from the strict quotas that were in effect, prospective migrants had to meet certain criteria, including literacy, age, skill, and health requirements (N. Abadan-Unat, R. Keleş, R. Penninx, H. Van Renselaar, L. Van Velzen, and L. Yenisey, eds., Migration and Development [Ankara: Ajans-Türk Press, 1975], pp. 5-9). An extensive survey of the evidence on external migration from Turkey may be found in Ç. Keyder and A. Aksu-Koç, "External Labor Migration from Turkey and Its Impact: An Evaluation of the Literature," Manuscript Report 185e (International Development Research Centre, Ottawa, 1988).

14. Details are reported in I. Tunal,, "Migration and Remigration as Inter- 
dependent Decisions: A Bivariate Probit Formulation," Department of Economics Working Paper no. 408 (Cornell University, Ithaca, N.Y., May 1938).

15. The terminology is due to $\mathrm{Da}$ Vanzo and Morrison, who refer to factors that tie an individual to a particular place as "location-specific capital" (Da Vanzo, "Repeat Migration, Information Costs, and Location-Specific Capital"; and Da Vanzo and Morrison, "Return and Other Sequences of Migration in the United States").

16. J. C. Caldwell, African Rural Urban Migration: The Movement to Ghana's Towns (New York: Columbia University Press, 1969); E. S. Lee, "Migration in Relation to Education, Intellect and Social Structure," Population Index 36 (October-December 1970): 437-44; M. Levy and W. Wadycki, "Education and the Decision to Migrate: An Econometric Analysis of Migration in Venezuela," Econometrica 42 (March 1974): 377-88; Y. Mundlak, "Occupational Migration Out of Agriculture-a Cross-Country Analysis," Review of Economics and Statistics 60 (August 1978): 392-98; R. Pryor, Jr., Migration and Development in South-East Asia: A Demographic Perspective (New York: Oxford University Press, 1979); W. J. House and H. Rempel, "The Determinants of Interregional Migrations in Kenya" World Development 8(January 1980): 25-35; T. P. Schultz, "Lifetime Migration within Educational Strata in Venezuela: Estimates of a Logistic Model," Economic Development and Cultural Change 30 (April 1982): 559-93, and "Notes on the Estimation of Migration Decision Functions," in Migration and the Labor Market in Development Countries, ed. R. H. Sabot (Boulder, Colo.: Westview, 1982).

17. The same pattern is reported by J. Da Vanzo and P. A. Morrison, Migration Sequences: Who Moves Back and Who Moves On? (Santa Monica, Calif.: Rand Corporation, 1982); and A. B. Simmons and R. G. Cardona, "Rural-Urban Migration: Who Comes, Who Stays, Who Returns? The Case of Bogotá, Colombia, 1929-1968," International Migration Review 6 (Spring 1972): 166-81.

18. A detailed examination of the links between unemployment and migration is provided by J. Da Vanzo, "Does Unemployment Affect Migration? Evidence from Micro Data," Review of Economics and Statistics 60 (November 1978): 504-11.

19. There is international evidence in favor of what some authors have called bimodal selectivity in terms of occupation, whereby high migration propensities are attached to high-skill as well as no-skill groups-see M. J. Carvajal and D. T. Geithman, "An Economic Analysis of Migration in Costa Rica," Economic Development and Cultural Change 23 (October 1974): 105-22; T. G. McGee, "Rural-Urban Mobility in South and Southeast Asia: Different Formulations, Different Answers," in Human Migration: Patterns and Policies, ed. W. H. McNeil and R. S. Adams (Bloomington: Indiana University Press, 1978), pp. 199-224; Pryor; M. Lipton, "Migration from Rural Areas of Poor Countries: The Impact of Rural Productivity and Income Distribution," World Development 8 (January 1980): 1-23. My results also suggest the same pattern, since unemployment and lack of job security are common experiences of nonskilled individuals.

20. To check the validity of this interpretation, I included total labor market experience in the migration equations. Consistent with the human capital interpretation, the coefficient on experience was positive and statistically significant $(P$-value $<.01)$. Both AGE and TEN lost their statistical significance. A detailed investigation of the migration-human capital link is undertaken by K. L. Shaw, "The Influence of Human Capital Investment on Migration and Industry Change," Journal of Regional Science 31 (November 1991): 397-416, who breaks specific human capital into three components: industry- 
specific, occupation-specific, and employer-specific. She finds that investment in industry and occupational skills decreases mobility during the initial years of attachment but eventually increases mobility. Her interpretation is that individuals begin to seek out new opportunities as the returns to their investment begin to fall. In my experimentations I detected mild nonlinearities of this sort in the 5-year samples but not in the 10-year samples.

21. This point is due to A. Bartel, "The Migration Decision: What Role Does Job Mobility Play?"' American Economic Review 69 (December 1979): 775-86. Truncation of TEN by length of residence (DUR), and interaction of TEN by a transfer dummy - which was set equal to one if DUR > TEN and zero otherwise-did not alter the finding that migration and remigration probabilities increase with tenure. This suggests that both interpretations invoked in the text are valid.

22. Interprovince flow data are from I. Tekeli, "Türkiyede Göç Vektörlerinin 1960-75 Döneminde Yönlülük Analizi ve Mekan Organizasyonunda Uyum Sürecinin Yönü" (Directional analysis of migration vectors during 1965-70 in Turkey and the direction of adjustment in settlement distribution), in Tekeli and Erder (n. 1 above), pp. 271-95.

23. See A. Schwartz, "Interpreting the Effect of Distance on Migration," Journal of Political Economy 81 (October 1973): 1977-88; and Yezer and Thurston (n. 8 above). A thorough discussion of the role distance plays in the human capital framework may be found in D. E. Clark and J. C. Cosgrove, "Amenities versus Labor Market Opportunities: Choosing the Optimal Distance to Move," Journal of Regional Science 31 (August 1991): 311-28.

24. This is a widely used measure of distance in regional sciences. See Gedik, "A Causal Analysis of the Destination Choice of Village to Province-" Center Migrants in Turkey, 1965-70" (n. 1 above).

25. The indexes are reported in B. Tolan, Türkiye'de Iller Itibariyle Sosyo-Ekonomik Gelişmişlik Endeksi (1963-70) (Socioeconomic development indexes by province in Turkey [1963-70]) (Ankara: T. C. Başbakanlık Devlet Planlama Teşkilatı, 1972).

26. Various channels through which age influences migration probabilities are examined by P. Lundborg, "An Interpretation of the Effects of Age on Migration: Nordic Migrants' Choice of Settlement in Sweden," Southern Economic Journal 58 (October 1991): 392-405. Lundborg finds that age interacts with wage, employment probability, and costs of migration. D. E. Clark and W. J. Hunter, "The Impact of Economic Opportunity, Amenities and Fiscal Factors of Age-Specific Migration Rates," Journal of Regional Science 32 (August 1992): 349-65, investigate the influence of explanatory variables on age-specific migration rates of white males over their life-cycle. They find that labor market factors figure in most significantly during the working years. Amenities have a larger influence on the middle-aged and older cohorts compared with younger ones.

27. See Karpat (n. 1 above); and Kartal (n. 1 above).

28. Using 5-year province-level figures, each year spent at the beginningof-the-period locality will have a net contribution of $(-0.0471)+(-0.0466)$ $+(0.0263)=-0.0674$ to the argument of the probability distribution assuming continual employment. Hence, it will take $0.54 / 0.0674 \cong 8$ years to offset the contribution of RURAL to the argument. By including TEN into the example, I am assuming that the individual will stay employed in the same occupation.

29. This is calculated from eq. (A5) in the appendix using the estimated coefficient of UNEMP in the first col. of table 2 and setting $\Delta \mathbf{x}_{\mathrm{k}}=1$.

30. Tolan (n. 25 above).

31. These calculations are based on rather extreme changes in the AIOD 
and DOD values. The AIOD variable has a mean value of 41 kilometers and range of 24-89 kilometers; furthermore, its frequency distribution is heavily skewed to the right. For the $1970-75$ period, Gedik reports the mean distance traveled by out-migrants as 344 kilometers and the range as 67-934 kilometers ("A Causal Analysis of the Destination Choice of Village to Province-Center Migrants in Turkey, 1965-70," p. 117). The frequency distribution is once again heavily skewed to the right. Hence, for most individuals, the distance variables are likely to have a smaller impact on the migration decision than those suggested by my examples.

32. The last proposition is due to Da Vanzo, "Repeat Migration, Information Costs, and Location-Specific Capital" (n. 8 above); and Da Vanzo and Morrison, "Return and Other Sequences of Migration in the United States" (n. 8 above).

33. See Gedik, "Rural to Urban versus Urban to Urban Migration in Turkey" ( $n$. 1 above); Kartal; Danielson and Keleş (n. 1 above); and Tanfer (n. 1 above).

34. Evidence from diverse settings suggest that networks that develop over time influence the timing and directionality of migration flows and the likelihood of a successful move. See B. Banarjee, "Rural-Urban Migration and Family Ties: An Analysis of Family Considerations in Migration Behaviour in India," Oxford Bulletin of Economics and Statistics 43 (November 1981): 32156; J. E. Taylor, "Differential Migration, Networks, Information, and Risk," in Research in Human Capital and Development: Migration, Human Capital, and Development, ed. O. Stark and I. Sirageldin (Greenwich, Conn.: JAI, 1986), 4:147-71; Shields and Shields (n. 12 above). In the Turkish setting, this pattern is noted by Karpat; and Kartal. Two-thirds of the rural-urban migrants in the full ("Male Survey," HIPS, 1973) sample reported having relatives or fellow villagers at their destination. One-third of these stayed with relatives and acquaintances. Nearly one-third of all rural-urban migrants indicated that they hosted others from their village for prolonged periods of time.

35. Tunalı, "Migration and Remigration as Interdependent Decisions" (n. 14 above). 
Copyright of Economic Development \& Cultural Change is the property of University of Chicago Press and its content may not be copied or emailed to multiple sites or posted to a listserv without the copyright holder's express written permission. However, users may print, download, or email articles for individual use. 